\title{
Functional and Neural Mechanisms of Embodiment: Importance of the Vestibular System and the Temporal Parietal Junction
}

\author{
B. Lenggenhager', S.T. Smith² and O. Blanke' \\ Laboratory of Cognitive Neuroscience, Brain Mind Institute, Ecole Polytechnique Fédérale de Lausanne \\ (EPFL), Lausanne, Switzerland and ${ }^{2}$ UCD School of Psychology, University College Dublin, Dublin, Ireland
}

SYNOPSIS

Embodiment, the sense of being localized within one's physical body, is a fundamental aspect of the self. Recent research shows that self and body processing as well as embodiment require distinct brain mechanisms. Here, we review recent clinical and neuroimaging research on multisensory perception and integration as well as mental imagery, pointing out their importance for the coding of embodiment at the temporo-parietal junction (TPJ). Special reference is given to vestibular mechanisms that are relevant for self and embodiment and to methods that interfere experimentally with normal embodiment. We conclude that multisensory and vestibular coding at the TPJ mediates humans' experience as being embodied and spatially situated, and argue that pathologies concerning the disembodied self, such as out-ofbody experience or other autoscopic phenomena, are due to deficient multisensory integration at the TPJ.

\section{KEY WORDS}

embodiment, self, body, temporo-parietal junction, autoscopic phenomena, vestibular processes

Accepted: 19 May, 2006

Reprint address:

Olaf Blanke

Laboratory of Cognitive Neuroscience

Brain Mind Institute, Station 15

Ecole Polytechnique Fdddrale de Lausanne (EPFL)

(Swiss Federal Institute of Technology)

1015 Lausanne, Switzerland

e-mail: olaf.blanke@epfl.ch

\section{INTRODUCTION}

In the cognitive neurosciences there is a renewal of interest in the very nature of subjective experience. Once suspect notions, such as consciousness, awareness, and mind, are again being intensively investigated. Consciousness, for example, is now variously being -'rediscovered' /84/, 'reconsidered' /32/, 'explained' /28/, or 'lost and found' /99/, leading many researchers from various fields to search for the 'neural correlates' of consciousness $/ 25,56,92 /$. More recently questions of self and selfawareness are also being investigated with respect to human consciousness. The self as an entity distinct from other human conspecifics may be described as an enduring and spatial entity (i.e. the feeling that one is the same person across time and space) to which certain mental events and actions are ascribed, such as the feeling of being author of one's own thoughts and actions (agency) and the feeling of being localized within one's body borders (embodiment or self location). A through understanding of a conscious experience will also have to incorporate findings concerning the self, i.e. the subject of that experience. What is the self? What has recent cognitive neuroscience revealed about the self?

Following earlier ontological and phylogenetic approaches to the study of the self $/ 38,39 /$, the nascent field of the cognitive neuroscience of the self tries to link several aspects of the self to distinct functional and neural mechanisms. Most research in cognitive neurosciences on the self has focused on agency $/ 22,33, /$, self/other distinction $/ 26 /$, selfrecognition /54,88,93/, visuo-spatial perspective taking /80,96/ and autobiographical memory /62/, and has been reviewed recently $/ 26,42 /$. The present review focuses on recent findings with respect to 
the localization of the self within one's bodily borders (here called embodiment). Although the average reader has probably never had any trouble localizing himself within his own bodily borders, this sense of embodiment requires specific brain mechanisms, that when disturbed may lead to states characterized by disembodied self-location, such as out-of-body experiences /7,19,29/. Here, we review recent clinical and neuroimaging research on multisensory perception and integration, vestibular perception, and mental imagery, pointing out their importance for the coding of embodiment in the temporo-parietal junction (TPJ). These aspects are presented in three sections: pathological forms of embodiment in neurological patients; normal embodiment in healthy subjects; and experimental methods to interfere with normal embodiment.

\section{PATHOLOGICAL EMBODIMENT IN NEUROLOGICAL PATIENTS}

One group of clinical phenomena seems especially fruitful with respect to the neuroscientific investigation of self and embodiment: autoscopic phenomena, including out-of.-body experience, autoscopic hallucination, and heautoscopy $/ 7,8,18 /$. During an autoscopic phenomenon, the individual experiences seeing a second own body in extracorporeal space associated with varying degrees of disembodiment between the self and the body (see below). Autoscopic phenomena challenge humans' everyday experience about the self and highlight that embodiment and self-location are related to distinct functions and brain mechanisms /9,69,70/. A better understanding of autoscopic phenomena might thus help to define the functions and brain structures mediating the self as embodied and as spatially situated.

The three autoscopic phenomena are defined as follows (see Fig. 1): During an out-of-body experience (OBE), people seem to be awake and feel that their 'self, or centre of awareness, is located outside the physical body and somewhat elevated (disembodiment). It is from this elevated extracorporeal location that subjects experience seeing their body and the world (for overview see /5,7,18,

For other definitions of embodiment see e.g. Wilson /98/.
29,50/). During an autoscopic hallucination ( $A H)$, people experience seeing a double of themselves in extrapersonal space without disembodiment. As compared to OBEs, individuals with $\mathrm{AH}$ experience seeing the world from their habitual and embodied visuo-spatial perspective and experience the 'self, or centre of awareness, inside their physical body. Finally, during heautoscopy (HAS), the individual has the experience of seeing a double of himself in extrapersonal space. However, it is difficult for the subject to decide whether or not he is disembodied, and whether the self is localized within the physical body or in the autoscopic body $/ 7 /$.

Autoscopic phenomena have been reported in various diseases of the central nervous system and may be due to generalized disease (meningitis, encephalitis, intoxication, generalized epilepsy) or focal disease (focal epilepsy, traumatic brain damage, migraine, vascular brain damage, neoplasia) $/ 7,19$, $27,29 /$. With respect to focal brain damage, early studies implicated posterior brain regions, including the temporal, parietal, or occipital lobe $/ 19,29 /$. More recently, Blanke and colleagues /6,7,10/ showed that $\mathrm{OBE}$ and HAS are primarily associated with damage at the temporo-parietal junction (TPJ), and $\mathrm{AH}$ with damage in the temporo-occipital cortex. This has been confirmed by Maillard et al. /63/, Brandt et al. /14/, and a recent review of 37 neurological patients with $\mathrm{OBE}, \mathrm{AH}$, or HAS due to focal brain damage (reported in the medical literature between 1923 and 2005) /8/. The analysis by Blanke and Mohr /8/ also suggested that autoscopic phenomena (AP) result from multisensory disintegration. Thus, Blanke et al. /7/ proposed that all autoscopic phenomena result from a disintegration in personal space (due to conflicting tactile, proprioceptive, kinesthetic, and visual information), and a second disintegration between personal and extrapersonal space (due to conflicting visual and vestibular information). These authors proposed that, while disintegration in personal space was present in all three forms of AP, differences between the different forms of AP were mainly due to differences in strength and type of the vestibular dysfunction. OBEs were associated with a strong vestibular disturbance, whereas HAS was associated with a moderate and more variable vestibular 


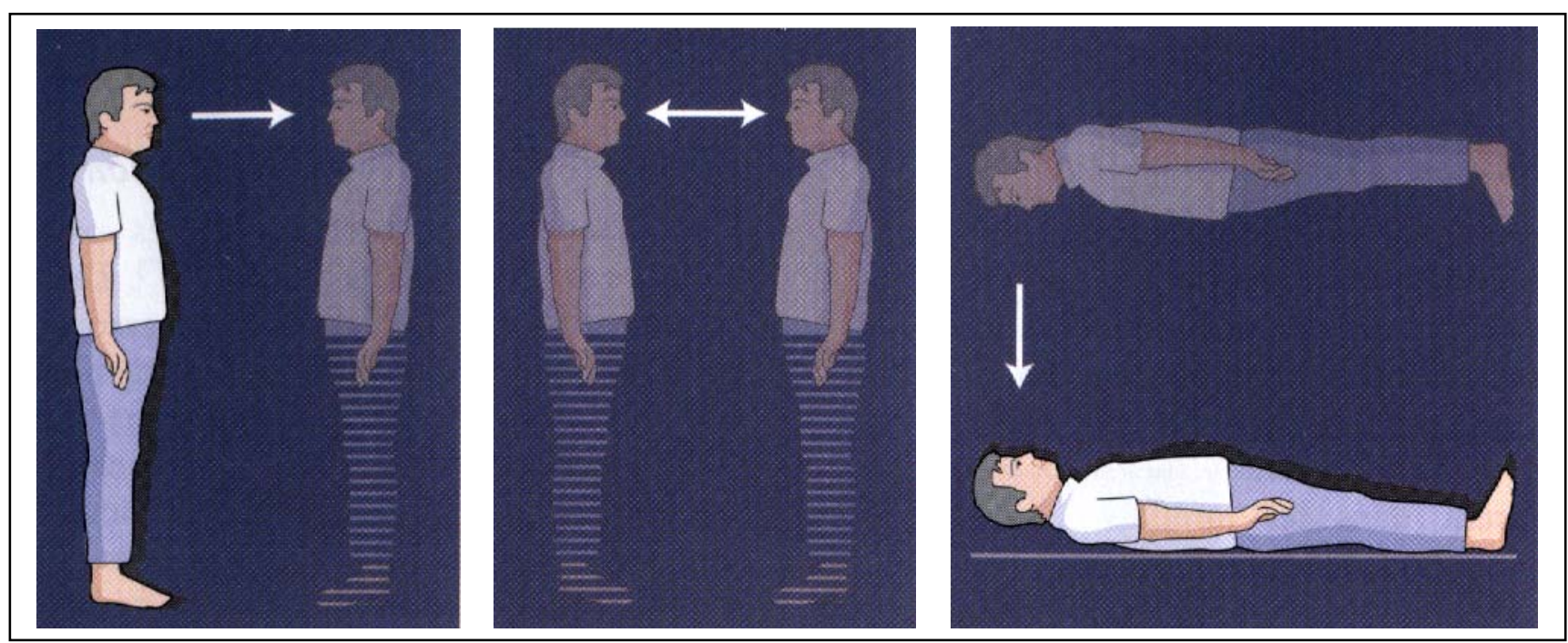

Fig. 1: Phenomenology of autoscopic phenomena. This figure illustrates the phenomenology of the three autoscopic phenomena: autoscopic hallucination (A), heautoscopy (B) and out-of-body experience (C). The position of the physical body of the subject is indicated as the non-transparent body, and the transparent body represents the illusory body. In autoscopic hallucinations the visuo-spatial perspective is body-centered or embodied; in out-of-body experience it is disembodied and from an extracorporeal location; and in heautoscopy it is either simultaneous or alternating between embodied and disembodied locations (see text for further explanations). Modified from Blanke et al. $17 /$.

disturbance, and $\mathrm{AH}$ without any vestibular disturbance $/ 7,8 /$. Moreover, the high frequency of visual hallucinations and hemianopia in patients with $\mathrm{AH}$ suggests that deficient visual processing is the main causative factor for disintegration in personal space in $\mathrm{AH}$. These data also suggest that HAS is primarily due to abnormal kinesthetic/proprioceptive information processing, whereas OBEs are due to abnormal vestibular information processing. Thus, HAS was associated with greater phenomenological variability of the autoscopic body, with increased frequency of shared thoughts, shared voices, and shared agency (between the autoscopic body and the patient's body), and varying degrees of disembodiment, suggesting that this might be due to a greater (or more variable) implication of abnormal kinesthetic/proprioceptive information processing in HAS. This is contrasted in OBEs with a silent and static autoscopic body, disembodiment, $180^{\circ}$ inversion and elevated visuo-spatial perspective, that are probably related to vestibular disturbances $/ 6 /$. To summarize, although all three autoscopic phenomena are due to disturbed multisensory integration at the TPJ, pathological embodiment in HAS and OBE seems to be due to distinct vestibular mechanisms that are associated (HAS) or not (OBE) with disturbed kinesthetic/ proprioceptive information processing $/ 6,8 /$.

\section{EMBODIMENT IN HEALTHY SUBJECTS}

The above model of autoscopic phenomena has been based on phenomenological, neuropsychological, and anatomical findings in neurological patients with $\mathrm{AH}, \mathrm{HAS}$, and $\mathrm{OBE}$, facilitating a formulation of precise research hypotheses about the multisensory and cognitive mechanisms of embodiment at the TPJ. In this section, we first review neuroimaging studies that have investigated the role of the TPJ in several aspects of processing with respect to body and self, and then present data on the TPJ's implication in embodiment.

Neuroimaging studies support the role of the TPJ in: (1) vestibular processing, (2) multisensory integration, and (3) the perception of human bodies or body $/ 6 /$. First, studies that have investigated the effects of vestibular stimulation in human cortex $/ 13,16,31,35,36,58,59,60,89 /$ described several dis- 
tinct vestibular areas revealing a core region in the posterior parieto-insular cortex including the TPJ /46/ (cf Fig. 2). In addition, brain damage in this area has been associated with graviceptive vestibular sensations and dysfunctions $/ 15 /$, and intracranial electrical stimulation at this site evoked vestibular sensations $/ 51,60,72 /$. Second, several neuropsychological and neuroimaging studies also suggest the implication of the TPJ and cortical areas along the intraparietal sulcus in combining tactile, proprioceptive, and visual information in a coordinated reference frame $/ 17,20,44 /$. Interestingly, Leube et al. /57/ have shown that the TPJ codes multisensory conflict or disintegration between visual and proprioceptive information about one's arm position. Thus, the presence of vestibular and multisensory processing at the site of lesions causing HAS and OBEs is concordant with the above proposed model of a disintegration at the TPJ in autoscopic phenomena. Third, the TPJ was found to be involved in the perception of several visual aspects of the human body, such as the perception of body parts $/ 11 /$ and of biological motion $/ 3,12,45,94 /$.
The TPJ has also been involved in functions of self-processing, such as egocentric visuo-spatial perspective taking, agency (the feeling of being the agent of one's actions and thoughts), as well as self/other distinction (the capacity by which one distinguishes between oneself and other conspecifics). For instance, the TPJ is the classical lesion site in patients with visuo-spatial neglect /48/, a clinical condition which has been shown to disturb the patient's egocentric spatial relationship with extrapersonal space and visuo-spatial perspective. Neuroimaging studies in healthy observers have also revealed activation of the TPJ during egocentric visuo-spatial perspective changes in healthy subjects /80,96/. The pathological visuospatial perspectives in OBEs and HAS might thus be related to disturbed functional systems at the TPJ that are involved in the constant updating and calculation of one's visuo-spatial perspective. Our observation that no changes in visuo-spatial perspective are reported by subjects with $\mathrm{AH}$ might accordingly be due to the fact that there is less or no TPJ involvement. Other studies have revealed the importance of the TPJ for mental activities such as

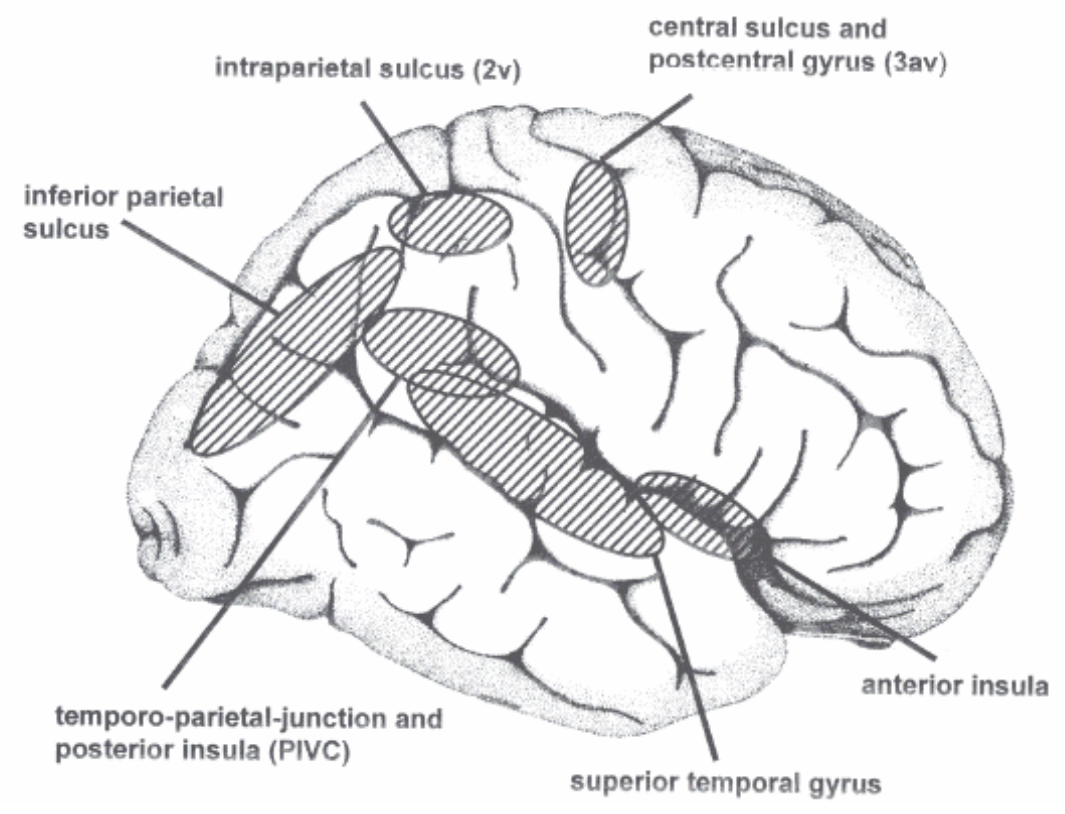

Fig. 2: Vestibular cortex. Distribution of the main vestibular cortical areas in humans (lateral view). Modified from Lopez et al. /60/; only the right hemisphere is shown. 
agency /22,33,34/ and self/other distinction /26/. Yet how do activity patterns of the TPJ relate to disembodiment and embodiment, and how can this be investigated neuroscientifically in humans?

In an evoked potential (EP) mapping study, Blanke et aL /9/ recently showed the selective activation of the TPJ at $330-400 \mathrm{~ms}$ after stimulus onset when healthy volunteers imagined themselves in the position and visual perspective that is generally reported by people experiencing spontaneous OBEs $/ 5 /$. They asked participants to imagine having the extracorporeal position and visuo-spatial perspective of a front- or back-facing schematic human figure. Participants had to decide whether the indicated hand would correspond to their right or left hand. In a control condition (lateralization task), the same visual stimuli were used, but participants decided whether the indicated hand was on the right or the left side of the computer screen (no imagined change in own-body position and visuo-spatial perspective). This condition was performed to dissociate central mechanisms of own body transformations (OBTs) and disembodiment from those attributable to the mere perception of the human body /30/ and right-left decisions. Participants took longer to perform the OBT task than the control task. In addition, reaction times (RTs) in the OBT task were longer for frontfacing figures than for back-facing figures (Fig. 3A). EP mapping of the mean EPs for the four conditions showed that brain activation at the TPJ (Fig. 3B) was longer in the OBT task than in the lateralization task, and longer for 'front-facing figures than for back-facing figures. The TPJ was predominantly activated in the right hemisphere. Activation of the TPJ was found in 10 subjects and included both TPJs in four subjects, only the right TPJ in four subjects, and only the left TPJ in two subjects (in one subject activation was found at the right temporo-occipital junction) (Fig. 3C).

Finally, in an epileptic patient with OBEs originating from the TPJ (Fig. 4A), we showed by the measurement of intracranial evoked potentials the partial activation of the seizure focus during the above-described OBT task that mimicked her visual perspective during her OBE percept. The activation was reflected by large intracranial evoked potentials at $330-400 \mathrm{~ms}$ after stimulus onset. These potentials were recorded at four electrode sites at the TPJ (Fig. 4B), which also showed amplitude differences between front-facing and back-facing (Fig. 4C). Collectively, these results suggested that the TPJ is a crucial structure for the conscious experience of the normal self as spatially embodied.

\section{DISTURBING EMBODIMENT IN NEUROLOGICAL PATIENTS AND HEALTHY SUBJECTS}

In this section we review three methods that might interfere with disembodiment in neurological patients and healthy subjects. These methods are: (1) electrical cortical stimulation in patients with epilepsy undergoing presurgical evaluation, (2) transcranial magnetic stimulation, and (3) galvanic vestibular stimulation in healthy subjects.

\section{Electrical cortical stimulation}

Recently, a patient has been reported /10/ in whom disembodiment (during an OBE), vestibular sensations, and visual body-part illusions could be induced by direct electrical cortical stimulation of the right hemisphere. In this patient, who underwent intracranial presurgical epilepsy evaluation for intractable seizures, focal electrical stimulation induced a classical OBE that was characterized by disembodiment, elevated visuo-spatial perspective, and autoscopy. The patient experienced that her self was localized under the ceiling and as if looking down on her body that was lying motionless on the bed. Repeated stimulations induced identical OBEs. Interestingly, smaller currents at this site led to vestibular sensations pointing to the importance of normal vestibular processing at the TPJ for human embodiment. Disembodiment and OBEs in this patient were induced whenever she looked straight ahead (without fixation of any specific object). If she fixated outstretched body parts during electrical stimulation, she had the impression that the inspected body part was transformed, leading to the illusory, but very realistic, visual perception of limb shortening or illusory limb movement if the limbs were bent at the elbow or knee /10/. Penfield described two presurgical patients with epilepsy with similar experiences (cases G.A. /73/ and V.F. 


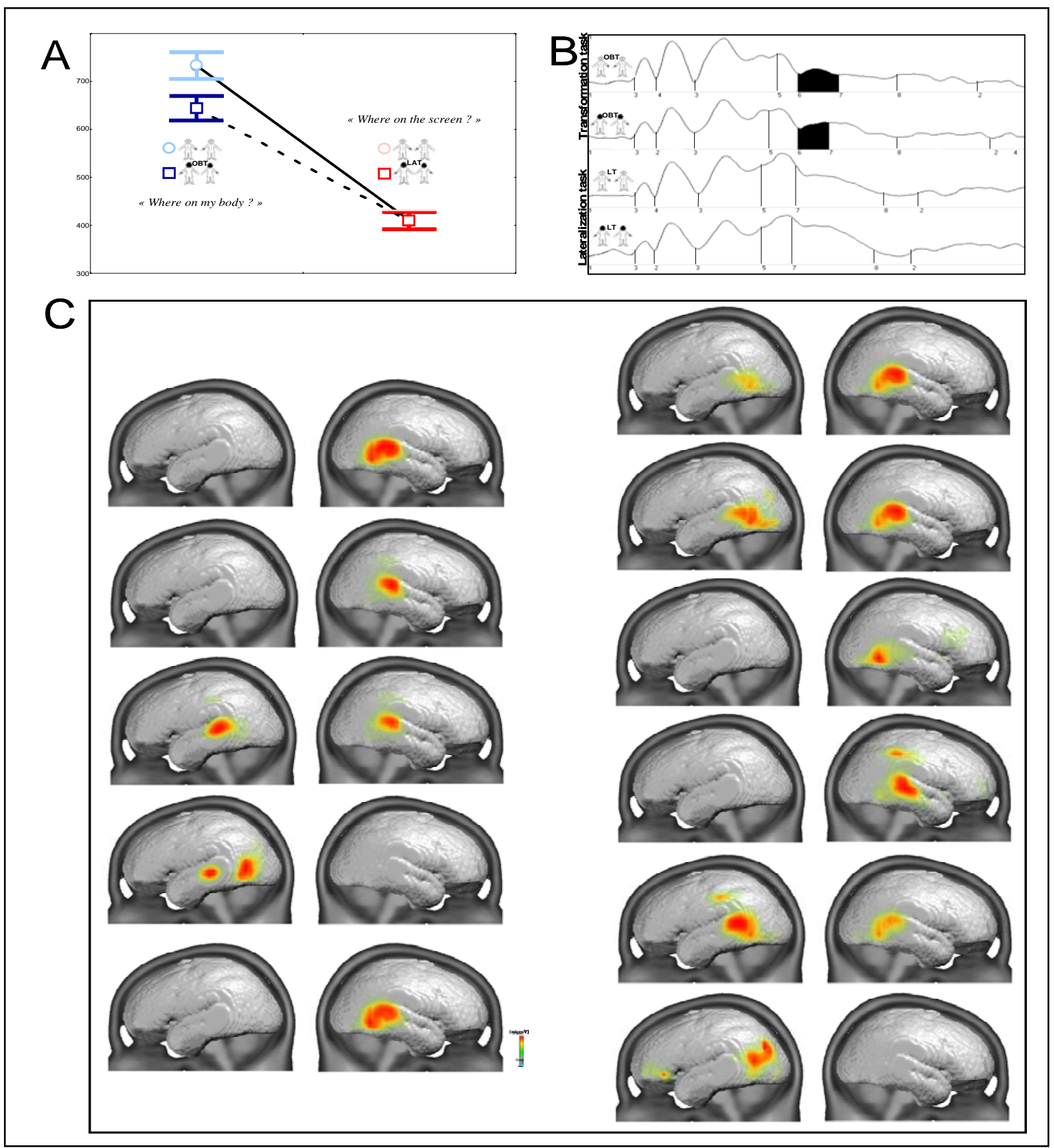

Fig. 3:Behavioral and EEG data during own body transformations. Behavioral and evoked potential data during an own body transformation (OBT) task and lateralization task in healthy subjects /9/. A. Reaction times in the OBT task (left) and the lateralization task (right). The reaction times (OBT task) are plotted separately for front-facing (upper) and back-facing (lower) figures. Note the longer reaction times for the OBT task. Front-facing figures during the OBT task, but not for the lateralization task, were characterized by longer reaction times with respect to back-facing figures. B. Segments of stable map topography in the four experimental conditions under the global field power curve from 0 to $700 \mathrm{~ms}$ are shown. Evoked potential map 6 (segment shown in black) was found from 330 to $400 \mathrm{~ms}$ and only in the OBT task. In addition, the duration of map 6 was found to be longer for front- than for back-facing figures. C. Localization of segment 6 is shown for each individual subject. Activation of the temporo-parietal junction (TPJ) was found in 10 subjects and included both TPJ in four subjects, only the right TPJ in four subjects, and only the left TPJ in two subjects. Modified from Blanke et al. /9/. (C) 2006 by the Society for Neuroscience. 

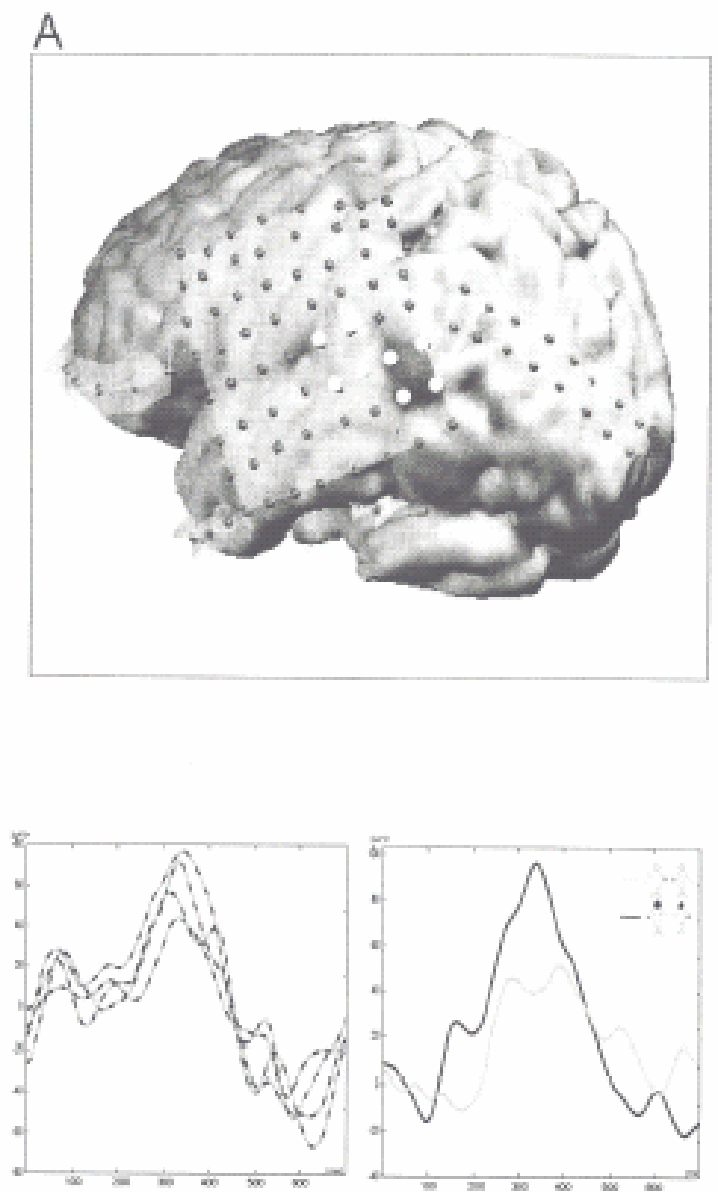

B

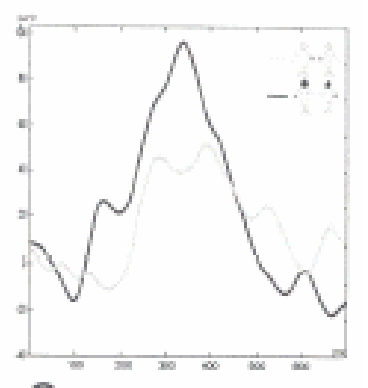

C
Fig. 4: Own body transformations in an epileptic patient with out-of-body experiences (OBEs). A. MRI with the implanted electrodes overlying the lateral convexity of the left hemisphere $/ 9 /$. The epileptic focus associated with OBEs is indicated by the eight white electrodes at the temporo-parietal junction (TPJ). B. Intracranial evoked potential amplitude for all implanted electrodes during the own body transformation (OBT) task is shown. The most prominent intracranial evoked potential peaked at $333 \mathrm{~ms}$ and was recorded at the TPJ, partly overlapping with the epileptic focus (A). C. Amplitude of the intracranial evoked potentials at an electrode at the TPJ differed between front-facing (light) and back-facing (dark). Modified from Blanke et aL /9/.C 2006 by the Society for Neuroscience.
/71/). Both patients had reported experiences strongly resembling OBEs while undergoing electrical cortical stimulation (Fig. 5). Yet, only little information was provided by Penfield for patient V.F. /91/, who exclaimed "Oh God! I am leaving my body." It was also not reported whether it was possible to reproduce the patient's experience. The sensation of 'leaving his body' was induced by electrical stimulation within the sylvian fissure on the surface of the superior temporal gyrus close to the insula, and the region of stimulation was within the patient's postoperative seizure focus. The stimulation that evoked the OBE-like experience also elicited a concurrent seizure, and it was only during the seizure that the patient exclaimed that he was 'leaving his body'. Interestingly, stimulation at a site $1 \mathrm{~cm}$ posterior to the '0130-inducing site elicited illusory whole body movements described as if he would be standing up or spinning around (resembling the patient's habitual aura). The descriptions of patient G.A.'s experiences /73/ were not autoscopic phenomena and may rather be described as illusory whole body and illusory contralateral arm movements. G.A. exclaimed that "I feel queer", asked "Am I here?", and described that she felt as if floating away and as if her left arm was moving. These experiences were reproducible, but induced at four different sites in the right hemisphere including the supramarginal gyrus and the superior temporal gyrus. G.A. suffered from focal epilepsy due to right hemispheric atrophy and local microgyria extending beyond the TPJ (frontal, upper and lower postcentral areas) and associated with contralesional corporeal atrophy. To summarize, there are thus not sufficient phenomenological details to classify both patients' experiences as autoscopic phenomena. In addition, both might have had substantial cortical reorganization at the sites whose stimulation resulted in OBE-like sensations (with various forms of disembodiment) since the epileptic focus was either very close or directly at the stimulation site. This was not the case in the patient described by Blanke et aL /10/. Despite these differences between Penfield's two patients and the patient of Blanke et aL /10/, there are a number of striking phenomenological similarities including pathological embodiment, vestibular sen- 


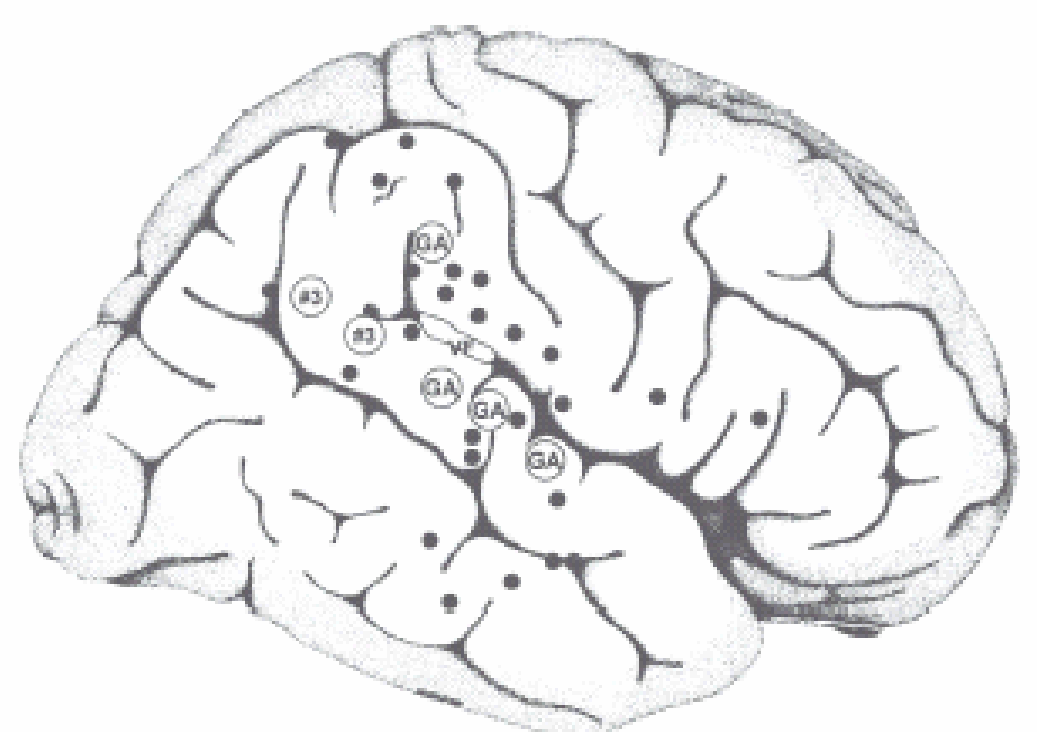

Fig. 5: Pathological embodiment and vestibular responses induced by intracranial stimulation. Location of different vestibular sensations and sensations of pathological embodiment such as out-of-body experiences is shown. Small dots represent stimulation sites where vestibular illusions were evoked /10,51/. Large dots indicate the sites where complex illusions of disembodiment and complex whole body displacements (/73/ patient G.A.; /71/ patient V.F.) as well as out-of-body experiences were evoked $/ 10 /$. All dots have been projected onto the right hemisphere even if vestibular responses were observed by stimulation in both hemispheres.

sations and visual body part illusions. Furthermore, all three cases were observed after stimulation of the right TPJ.

\section{Transcranial magnetic stimulation}

Using single pulse transcranial magnetic stimulation (TMS), we have recently extended our findings on disembodiment and OBEs due to disturbed TPJ activity and enhanced TPJ activation when healthy subjects mentally transform their body position into the position that is frequently reported by individuals with OBEs. They showed that interference with the TPJ by TMS impaired mental own body transformation in healthy subjects relative to TMS of a control site /9/ (see Fig. 6A). Furthermore, this functional interference by TPJ stimulation was task-specific and was not observed for mental transformations of the own body position into back-facing figures (not matching the classically experienced 'OBE position', see Fig. 6B left) and also not observed for a control task that implicated mental spatial transformations of other objects such as letters (Fig. 6B right). Thus, interference by TPJ stimulation with own body transformations did not generalize to other, nonbody spatial imagery tasks. It is worth mentioning that while TMS over TPJ selectively interfered with performance in the imagined body transformation task, TMS over the control site (intraparietal sulcus region) impaired mental object-based transformations. Together this was interpreted to support the notion that the TPJ plays an essential role in disembodiment and embodiment $/ 9 /$.

The converging evidence that the TPJ might play a key role for embodiment raises an interesting question. Is it possible to induce pathological states of embodiment in healthy volunteers corresponding to OBE or HAS through non-invasive TMS of the TPJ? Of particular interest in this regard are situations in which TMS can be considered to operate in a productive rather than disruptive mode, i.e. when TMS is generating a discernable peripheral response or a conscious percept. This is the 


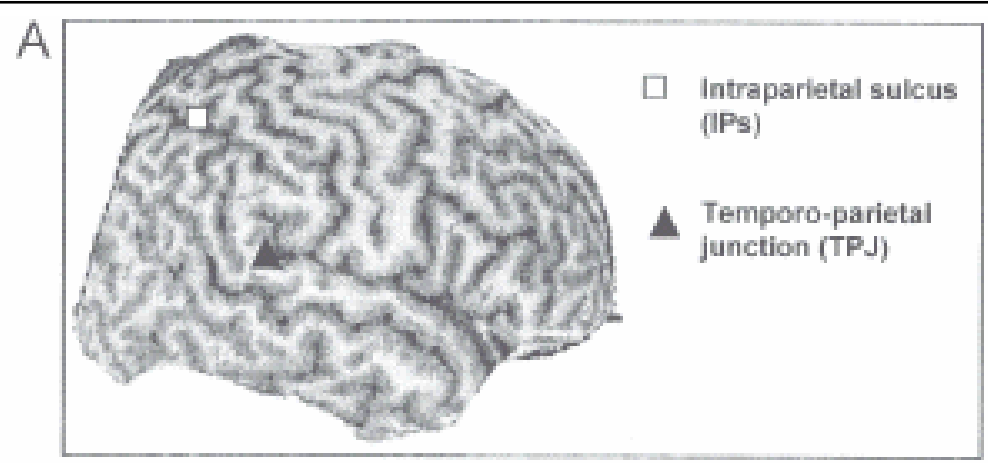

$\mathrm{B}$
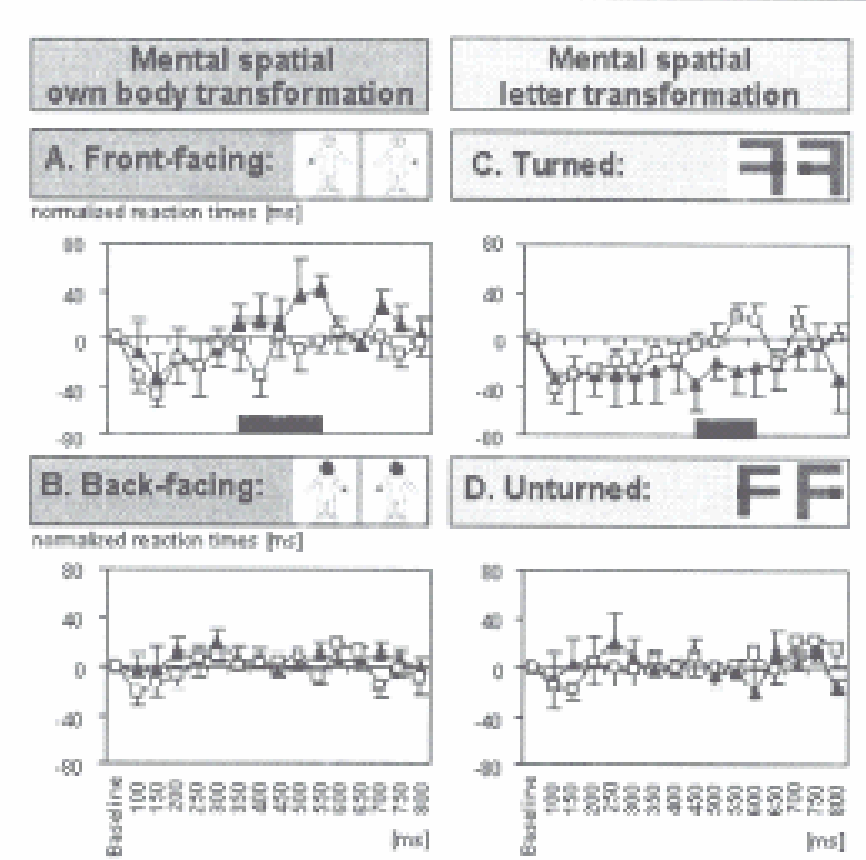

- - Tenporoporietal junction [TPJ)
-D- Conted site - Intraponex sulaus (IP5]

Fig. 6: Effects of transcranial magnetic stimulation (TMS) during own body transformations. A. TMS sites at the temporo-parietal junction (TPJ) and the intraparietal sulcus (IPS) are shown for one subject. B. Different stimuli and normalized reaction times for the investigated TMS pulse delays (100-800 ms after stimulus onset) for own body transformation (OBT) (left) and lateralization (LT) (right) tasks. The lower figures plot the reaction times (RTs) for back-facing human figures (OBT task) and unturned letters (LT task) when TMS is applied over TPJ (filled triangles) or IPS (open squares). The top figures show RTs for front-facing figures (OBT task) and turned letters (LT task). TMS of the TPJ and the IPS showed no effect to back-facing/unturned stimuli (lower figures). TMS of the TPJ showed slowed RTs to front-facing figures (OBT task) relative to IPS stimulation. This was only observed when TMS was applied between 350 and $550 \mathrm{~ms}$ after stimulus onset (top left plot). This was concordant with the evoked potential data (time period is indicated by black bar). TMS over IPS, in contrast, showed increased RTs to turned letters (LT task) relative to TPJ stimulation at TMS pulse delays of 450-600 ms (top right plot). Error bars indicate SEs. Modified from Blanke et al. /9/. (C) 2006 by the Society for Neuroscience. 
case for TMS over the motor cortex, which induces a muscle twitch in the contralateral face, arm, or foot, depending on the TMS site over the motor cortex $/ 1 /$. Other productive effects of TMS include transient paresthesia in the upper or lower extremities in response to stimulation of the contralateral sensorimotor cortex /1,2,23/ as well as stationary or moving phosphenes in the peripheral or bilateral visual fields in response to stimulation of striate and extrastriate visual cortex $/ 24,52,53$, 68/. To the best of our knowledge, TMS has never evoked productive effects when applied to higherorder association cortex, such as the TPJ. However, given that direct electrical cortical stimulation of this area can elicit disembodiment and OBEs $/ 10 /$, and given that these states occur spontaneously in the healthy population $/ 5,50 /$, we argue here that TMS over the TPJ is likely to interfere with embodiment in healthy subjects when TMS is applied in specific experimental settings. More precisely, we hypothesize that TMS at the TPJ could interfere with vestibular processing /67/ leading to sensations of pathological embodiment in conditions in which proprioceptive, tactile, visual and especially graviceptive vestibular inputs are weak or ambiguous. This is suggested by frequent vestibular illusions during weightlessness on space missions and the low gravity phase of parabolic flights, including the feeling of falling down, being upsidedown, of room-tilts, and the sensation of self- and surround motion $/ 47,55,97 /$. To further enhance spatial disorientation or disturb embodiment, especially concerning one's own body, visual and auditory input could be prevented by blindfolding the subjects and using a soundproofed room (sensory deprivation). Overall, these conditions might facilitate the induction of transient discrepant central representations of )tie's own body, suggested to be the neural basis of OBEs and other pathological forms of embodiment.

\section{Vestibular stimulation}

The possibility of interfering with induction of disturbed embodiment and potentially induce fullblown OBEs and related phenomena through vestibular stimulation is the final method that we would like to discuss. The vestibular system may be stimulated by such means as caloric vestibular stimulation, galvanic vestibular stimulation, and physiological vestibular stimulation. In addition, visual, tactile and proprioceptive stimulation may activate the vestibular system. Although these different stimuli have been used extensively to study the vestibular system, we here concentrate on galvanic vestibular stimulation $(G V S)^{1}$, as this simple technique: (1) has recently been used in a number of neuroimaging studies to activate the vestibular cortex including the TPJ, (2) allows precise experimental control, and (3) has been shown to induce a mismatch between actual and

\footnotetext{
${ }^{1}$ Purkinje /74/ was the first who systematically used GVS and described vertigo as a typical vestibular phenomenon. In the $19^{\text {th }}$ century researchers investigated the influence of GVS on postural and ocular responses in animal and humans (e.g. /49/) and clinical applications were discussed /61/. GVS is achieved by applying a small percutaneous current between the mastoid processes. Generally the stimulus is applied bilaterally and asymmetrically by an anodal electrode at one mastoid process and a cathodal electrode at the other mastoid process. The applied electrical stimulus increases the spontaneous firing of vestibular neurons at the cathodal side and decreases it at the anodal side. GVS is generally considered to modulate the hyperpolarization of the neuroepithelia of the cristae and maculae directly, bypassing the transduction mechanism of the hair cells /37/. GVS is a non-physiological vestibular stimulation due to the simultaneous interaction of the current with all afferents. Effects of GVS can be found in both vestibular subsystems /43/ and is supported by findings that GVS influences canal-induced and otolith-related eye movements in humans. Briefly, the semicircular canals are responsible for the perception of angular accelerations of the head. The three paired semicircular canals are approximately orthogonal and are therewith able to detect pitch, roll and yaw movements of the head. Although GVS evokes in the semicircular canals a firing pattern that has no natural rotational equivalent, Fitzpatrick and Day /37/ postulated that in sum it is a signal comparable to a rotation with yaw and most notably roll components toward the cathodal electrode. The otolith organs of the utricle and the saccule are responsible for the perception of linear acceleration such as gravity. The utricular macula codes predominately lateral and sagittal components of head acceleration, whereas the saccular macula codes signals with vertical and anteroposterior components. In the otholitic organs GVS increases the firing rates of both sides of the striola, which divides hair cells with different polarities. Because a larger number of receptors in each utricle respond to medially directed rather than laterally directed acceleration, this normally indicates acceleration to the cathodal side. The GVS-evoked signals in the sacculae from each side of the striola will largely cancel each other out. For further details see Fitzpatrick and Day /37/.
} 
subjective body position. Dependent on the nature of GVS stimulation, healthy subjects report selfmotion and displacement generally in the roll axis, less often in the yaw axis. Interestingly, most subjects feel whole body displacement and a few subjects just head displacement /87/. Generally there are at least three different responses to GVS in humans: (1) ocular responses, (2) postural responses, and (3) cognitive and perceptual effects. Keeping to the topic of this review on neural mechanisms of embodiment, we discuss the effects of GVS on perceptual and cognitive tasks, such as verticality judgment, own body transformation, and visuo-spatial perspective taking (for ocular and postural responses, see $/ 37,82 /$ ).

Verticality judgments, such as the subjective visual vertical and the subjective body orientation, have been shown to be dependant on vestibular signals. The subjective visual vertical is generally measured by asking subjects to orient a visual line to the vertical, whereas the subjective body orientation is measured by asking subjects to orient their own body with respect to the vertical. The subjective body orientation might thus be considered a measure of the orientation of the self with respect to the vertical. Both measures depend on the integration of visual, somatosensory, and vestibular inputs and are influenced by GVS. Thus, during GVS the subjective visual vertical appears inclined toward the anode /64/ and there is a more pronounced tilt of the subjective body orientation in the opposite direction. These findings suggest that vestibular cues are estimated as more reliable than somatosensory cues for the orientation and location of the self with respect to the body /4,64/. Based on these findings, we suggest that GVS might also be able to induce the experience of partial disembodiment (or a misalignment between physical body position and experienced body position or self [tilted towards the cathode]) presenting phenomenological similarities with OBEs and own body transformation tasks that have been used to study embodiment $/ 9 /$. We also speculate that GVS might be effective in influencing functional and neural mechanisms of embodiment, for example modifying task performance in mental own body transformations as described above $/ 9 /$. To our knowledge there is no study to date concerning the effects of GVS on mental own body transformations. However, Mast and Meissner /65/ showed that performance for mental own body transformations can be influenced when subjects are physically rotated during task performance. They found that subjects were more accurate when the directions of mental and physical body rotation were congruent. Additionally, Mast et $a L / 66 /$ investigated the influence of caloric vestibular stimulation on high resolution mental imagery. The study showed that this particular kind of mental rotation is impaired during caloric vestibular stimulation, while visual discrimination tasks without mental rotation were not affected, suggesting the presence of shared mechanisms and interactions between mental imagery and vestibular processing. Finally, GVS has also been found to interfere with visuospatial judgments, such as visuo-spatial perspective taking, that are disturbed in OBEs (see above) and that have been linked functionally and anatomically to the posterior parietal cortex including the TPJ. This might also be a reason for the previously shown influences of vestibular stimulation on visuospatial judgments, such as line bisection in neurological patients with visuo-spatial neglect /21,40,76-79,95/ and in healthy subjects /81,83/. This has been shown more directly by Fink and colleagues /36/ who observed interactions of GVS with visuo-spatial judgments in right posterior parietal and right ventral premotor cortex.

\section{CONCLUSION}

In science the most challenging phenomena are often the ones we take for granted in our everyday lives. Excellent examples are the self, the experience of spatial unity (between self and body), and thus the everyday experience of being spatially embodied. Both folk psychological notions are challenged by autoscopic phenomena. The reviewed evidence from neurological patients experiencing these striking dissociations between self and body suggests that autoscopic phenomena are culturally invariant phenomena, which can be investigated scientifically to further our understanding of the functional and neural mechanisms of embodiment. This has recently been shown in a series of experiments linking the TPJ to self- 
location, embodiment and visuo-spatial perspective. In addition, TMS and GVS may be used to interfere with the central mechanisms of embodiment. The neuroscientific study of the self is in its infancy and there are currently no established models, very few data, and often not even the vocabulary to describe neuroscientific notions of the self. The investigation of autoscopic phenomena and embodiment in specific neurological patients and healthy subjects as well as the functional and neural mechanisms involved might thus allow improvement of our neuroscientific models of embodiment, self and subjectivity.

\section{ACKNOWLEDGEMENTS}

The authors are supported by Fondation Odier, Fondation de Famille Sandoz and the Cogito Foundation.

\section{REFERENCES}

1. Amassian VE, Cracco RQ, Maccabee PJ, Cracco JB, Henry K. Some positive effects of transcranial magnetic stimulation. Adv Neural 1995; 67: 79-106.

2. Amassian VE, Somasundaram M, Rothwell JC, Britton T, Cracco JB. Paraesthesias are elicited by single pulse, magnetic coil stimulation of motor cortex in susceptible humans. Brain 1991; 114: 2505-2520.

3. Beauchamp MS, Lee KE, Haxby JV, Martin A. Parallel visual motion processing streams for manipulable objects and human movements. Neuron 2002; 34: 149159.

4. Bisdorff AR, Wolsley CJ, Anastasopoulos D, Bronstein AM, Gresty MA. The perception of body verticality (subjective postural vertical) in peripheral and central vestibular disorders. Brain 1996; 119: 1523-1534.

5. Blackmore S. Beyond the Body. An Investigation of Outof-Body Experiences. London: Heinemann, 1982.

6. Blanke 0, Arzy S. The out-of-body experience: disturbed self-processing at the temporo-parietal junction. Neuroscientist 2005; 11: 16-24.

7. Blanke 0, Landis T, Spinelli L, Seeck M. Out-of-body experience and autoscopy of neurological origin. Brain 2004; 127: 243-258.

8. Blanke 0, Mohr C. Out-of-body experience, heautoscopy, and autoscopic hallucination of neurological origin. Implications for neurocognitive mechanisms of corporeal awareness and self-consciousness. Brain Res Brain Res Rev 2005; 50: 184-199.
10. Blanke 0, Mohr C, Michel CM, Pascual-Leone A, Brugger P, Seeck M, Landis T, Thut G. Linking outofbody experience and self processing to mental own-body imagery at the temporoparietal junction. J Neurosci 2005; 25: 550-557.

11. Blanke 0, Ortigue S, Landis T, Seeck M. Stimulating illusory own-body perceptions. Nature 2002; 419: 269270.

12. Bonda E, Petrides M, Frey S, Evans A. Neural correlates of mental transformations of the body-in-space. Proc Natl Acad Sci USA 1995; 92: 11180-11184.

13. Bonda E, Petrides M, Ostry D, Evans A. Specific involvement of human parietal systems and the amygdala in the perception of biological motion. J Neurosci 1996; 16: 3737-3744.

14. Bottini G, Sterzi R, Paulesu E, Vallar G, Cappa SF. Identification of the central vestibular projections in man: a positron emission tomography activation study. Exp Brain Res 1994; 99: 164-169.

15. Brandt C, Brechtelsbauer D, Bien CG, Refiners K. Outof-body experience as possible seizure symptom in a patient with a right parietal lesion. Nervenarzt 2005; 76: 1259-1262.

16. Brandt T. Central vestibular disorders. In: Vertigo: Its Multisensory Syndromes, London: Springer, 2000; 146167.

17. Brandt T, Dieterich M. The vestibular cortex. Its locations, functions, and disorders. Ann NY Acad Sci 1999; 871: 293-312.

18. Bremmer F, Schlack A, Duhamel JR, Graf W, Fink GR. Space coding in primate posterior parietal cortex. Neuroimage 2001; 14: S46-51.

19. Brugger P. Reflective mirrors: perspective taking in autoscopic phenomena. Cogn Neuropsychiatry 2002; 7: 179-194.

20. Brugger P, Regard M, Landis T. Illusory reduplication of one's own body: phenomenology. Classification of autoscopic phenomena. Cogn Neuropsychiatry 1997; 2: 19-38.

21. Calvert GA, Campbell R, Brammer MJ. Evidence from functional magnetic resonance imaging of crossmodal binding in the human heteromodal cortex. Cuff Biol 2000; 10: 649-657.

22. Cappa S, Sterzi R, Vallar G, Bisiach E. Remission of hemineglect and anosognosia during vestibular stimulation. Neuropsychologia 1987; 25: 775-782.

23. Chaminade T, Decety J. Leader or follower? Involvement of the inferior parietal lobule in agency. NeuroReport 2002; 13: 1975-1978.

24. Cohen LG, Topka H, Cole RA, Hallett M. Leg paresthesias induced by magnetic brain stimulation in patients with thoracic spinal cord injury. Neurology 1991; 41: 1283-1288.

25. Cowey A, Walsh V. Magnetically induced phosphenes in sighted, blind and blindsighted observers. NeuroReport 2000; 11: 3269-3273. 
25. Crick F, Koch C. The problem of consciousness. Sci Am 1992;267:152-159.

26. Decety J, Sommerville JA. Shared representations between self and other: a social cognitive neuroscience view. Trends Cogn Sci 2003; 7: 527-533.

27. Dening TR, Berrios GE. Autoscopic phenomena. Br J Psychiatry 1994; 165: 808-817.

28. Dennett D. Consciousness Explained. New York: Little, Brown, 1991.

29. Devinsky 0, Feldmann E, Burrowes K, Bromfield E. Autoscopic phenomena with seizures. Arch Neurol 1989; 46: 1080-1088.

30. Downing PE, Jiang Y, Shuman M, Kanwisher N. A cortical area selective for visual processing of the human body. Science 2001; 293: 2470-2473.

31. Emri M, Kisely M, Lengyel Z, Balkay L, Marian T, et al. Cortical projection of peripheral vestibular signaling. J Neurophysiol 2003; 89: 2639-2646.

32. Flanagan O. Consciousness Reconsidered. Cambridge, MA: MIT Press, 1992.

33.Farrer C, Franck N, Georgieff N, Frith CD, Decety J, Jeannerod M. Modulating the experience of agency: a positron emission tomography study. Neuroimage 2003; 18: 324-333.

34.Farrer C, Frith CD. Experiencing oneself vs another person as being the cause of an action: the neural correlates of the experience of agency. Neuroimage 2002; 15: 596-603.

35.Fasold 0, von Brevern M, Kuhberg M, Ploner CJ, Villringer A, et al. Human vestibular cortex as identified with caloric stimulation in functional magnetic resonance imaging. Neuroimage 2002; 17: 1384-1393.

36.Fink GR, Marshall JC, Weiss PH, Stephan T, Grefkes C, et al. Performing allocentric visuospatial judgments with induced distortion of the egocentric reference frame: an fMRI study with clinical implications. Neuroimage 2003;20:1505-1517.

37. Fitzpatrick RC, Day BL. Probing the human vestibular system with galvanic stimulation. J Appl Physiol 2004; 96: 2301-2316.

38. Gallup GG. Chimpanzees: self-recognition. Science 1970; 167: 86-87.

39. Gallup GG. Self-awareness and the emergence of mind in primates. Am J Primatol 1982; 2: 237-248.

40.Geminiani G, Bottini G. Mental representation and temporary recovery from unilateral neglect after vestibular stimulation. J Neurol Neurosurg Psychiatry 1992; 55: 332-333.

41. Genner T. Das Sehen des eigenen Spiegelbildes als epileptisches Aquivalent. Wiener klin Wochenschr 1947; 59: 656-658.

42. Gillihan SJ, Farah MJ. Is self special? A critical review of evidence from experimental psychology and cognitive neuroscience. Psychol Bull 2005; 131: 76-97.

43. Goldberg, JM, Smith CE, Fernandez C. Relation between discharge regularity and responses to externally applied galvanic currents in vestibular nerve afferents of the squirrel monkey. J Neurophysiol 1984; 51: 1236 1256.

45. Grefices C, Fink GR. The functional organization of the intraparietal sulcus in humans and monkeys. J Anat 2005; 207: 3-17.

46. Grossman ED, Blake R. Brain areas active during visual perception of biological motion. Neuron 2002; 35: 1167 1175.

47. Guldin WO, Grusser OJ. Is there a vestibular cortex? Trends Neurosci 1998; 21: 254-259.

48. Gurovskiy NN, Bryanov II, Yegorov AD. Changes in the vestibular function during space flight. Acta Astronaut 1975; 2: 207-216.

49. Halligan PW, Fink GR, Marshall JC, Vallar G. Spatial cognition: evidence from visual neglect. Trends Cogn Sci 2003; 7: 125-133.

50. Hitzig E. Der Schwindel [Vertigo]. Wien: Alfred Hölder, 1898.

51. Irwin H. Flight of Mind: A Psychological Study of the Out-of-Body Experience. Metuchen, NJ: Scarecrow Press, 1985.

52. Kahane P, Hoffmann D, Minotti L, Berthoz A. Reappraisal of the human vestibular cortex by cortical electrical stimulation study. Ann Neurol 2003; 54: 615-624.

53.Kammer T. Phosphenes and transient scotomas induced by magnetic stimulation of the occipital lobe: their topographic relationship. Neuropsychologia 1999; 37: 191-198.

54.Kammer T, Beck S, Thielscher A, Laubis-Herrmann U, Topka H. Motor thresholds in humans: a transcranial magnetic stimulation study comparing different pulse waveforms, current directions and stimulator types. Clin Neurophysiol 2001; 112: 250-258.

55. Keenan JP, Nelson A, O'Connor M, Pascual-Leone A. Self-recognition and the right hemisphere. Nature 2001; 409: 305.

56. Komilova LN. Orientation illusions in spaceflight. J Vestib Res 1997; 7: 429-439.

57.Laureys S. Science and society: death, unconsciousness and the brain. Nat Rev Neurosci 2005; 6: 899-909.

58.Leube DT, Knoblich G, Erb M, Grodd W, Bartels M, Kircher TT. The neural correlates of perceiving one's own movements. Neuroimage2003; 20: 2084-2090.

59.Lobel E, Kleine JF, Bihan DL, Leroy-Willig A, Berthoz A. Functional MRI of galvanic vestibular stimulation. J Neurophysiol 1998; 80: 2699-2709.

60.Lobel E, Kleine JF, Leroy-Willig A, Van de Moortele $\mathrm{PF}$, Le Bihan D, et al. Cortical areas activated by bilateral galvanic vestibular stimulation. Ann NY Acad Sci 1999;871:313-323.

61.Lopez C, Lacour C, Borel L. Perception de la verticalité et représentations spatiale daps les arras corticales vestibulaires. In: Lacour M, Weber B. Bipddie eds: Contr6le Postural et Representation Cortical. Marseille: Solal, 2005; 35-86.

62. Mackenzie G. Klinische Studien fiber die Funktionsprofungen des Labyrinthes mittels des galvanischen 
Stroms. Arch Ohren-, Nasen- and Kehlkopfheilk 1908; 1-18.

62. Maguire EA, Cipolotti L. Selective sparing of topographical memory. J Neurol Neurosurg Psychiatry 1998; 65: 903-909.

63. Maillard L, Vignal JP, Anxionnat R, Taillandier Vespignani L. Semiologic value of ictal autoscopy. Epilepsia 2004; 45: 391-394.

64. Mars F, Vercher JL, Popov K. Dissociation between subjective vertical and subjective body orientation elicited by galvanic vestibular stimulation. Brain Res Bull 2005; 65: 77-86.

65. Mast FW, Meissner F. Mental transformations of perspective during whole-body roll-rotation. Presented at 23'd Barany Society Meeting, Paris, 2004.

66. Mast FW, Merfeld DM, Kosslyn SM. Visual mental imagery during caloric vestibular stimulation. Neuropsychologia 2006; 44: 101-109.

67. Matsuhashi M, Ikeda A, Ohara S, Matsumoto R, Yamamoto J, et al. Multisensory convergence at human temporo-parietal junction - epicortical recording of evoked responses. Clin Neurophysiol 2004; 115: 1145-1160.

68. Meyer BU, Diehl R, Steinmetz H, Britton TC, Benecke R. Magnetic stimuli applied over motor and visual cortex: influence of coil position and field polarity on motor responses, phosphenes, and eye movements. Electroencephalogr Clin Neurophysiol 1991; Suppl 43: 121 134.

69. Metzinger T. Being No One. Cambridge, MA: MIT Press, 2003.

70. Neisser U. The five kinds of self-knowledge. Phil Psychol 1988; 1: 35-59.

71. Penfield W. The twenty-ninth Maudsley lecture: The role of the temporal cortex in certain psychical phenomena. J Merit Sci 1955; 451-465.

72. Penfield W. Vestibular sensation and the cerebral cortex. Ann Otol Rhinol Laryngol 1957; 66: 691-698.

73. Penfield W, Erickson TC. Epilepy and Cerebral Localization. A Study of the Mechanism, Treatment and Prevention of Epileptic Seizures. Springfield, IL: Charles C Thomas, 1941; 122-124, 261-265.

74. Purkinje JE. Beyträge zur näheren Kenntnis des Schwindels aus heautognostischen Daten. Medicinische Jahrbücher des kaiserlich-k6niglichen 6sterreichischen Staates 1820; 6: 79-125.

75. Ratcliff G. Spatial thought, mental rotation and the right cerebral hemisphere. Neuropsychologia 1979; 17: 49-54.

76. Rode G, Charles N, Perenin MT, Vighetto A, Trillet M, Aimard G. Partial remission of hemiplegia and somatoparaphrenia through vestibular stimulation in a case of unilateral neglect. Cortex 1992; 28: 203-208.

77. Rode G, Perenin MT, Honore J, Boisson D. Improvement of the motor deficit of neglect patients through vestibular stimulation: evidence for a motor neglect component. Cortex 1998; 34: 253-261.
79. Rorsman 1, Magnusson M, Johansson BB. Reduction of visuo-spatial neglect with vestibular galvanic stimulation. Scand J Rehabil Med 1999; 31: 117-124.

80. Rubens AB. Caloric stimulation and unilateral visual neglect. Neurology 1985; 35: 1019-1024.

81. Ruby P, Decety J. Effect of subjective perspective taking during simulation of action: a PET investigation- of agency. Nat Neurosci 2001; 4: 546-550.

82. Sandor PS, Bachtold D, Henn V, Brugger P. Effects of optokinetically induced rotatory self-motion on spatial perception and representation. Neuropsychiatry Neuropsychol Behav Neurol 2000; 13: 188-194.

83. Schneider E, Glasauer S, Dieterich M Central processing of human ocular torsion analyzed by galvanic vestibular stimulation. NeuroReport. 2000; 11: 1559-1563.

84. Schueli H, Henn V, Brugger P. Vestibular stimulation affects dichotic lexical decision performance. Neuropsychologia 1999; 37: 653-659.

85. Searle JB. When is a species not a species? Curr Biol 1992; 2: 407-409.

86. Shuren J, Hartley T, Heilman KM. The effects of rotation on spatial attention. Neuropsychiatry Neuropsychol Behav Neurol 1998; 11: 72-75.

87. Smith BH. Vestibular disturbances in epilepsy. Neurology 1960; 10: 465-469.

88. Stephan T, Deutschlander A, Nolte A, Schneider E, Wiesmann M, Brandt T, Dieterich M. Functional MRI of galvanic vestibular stimulation with alternating currents at different frequencies. Neuroimage 2005; 26: 721-732.

89. Sugiura M, Watanabe J, Maeda Y, Matsue Y, Fukuda H, Kawashima R. Cortical mechanisms of visual selfrecognition.. Neuroimage 2005; 24: 143-149.

90. Suzuki M, Kitano H, Ito R, Kitanishi T, Yazawa Y, et al. Cortical and subcortical vestibular response to caloric stimulation detected by functional magnetic resonance imaging. Brain Res Cogn Brain Res 2001; 12: 441-449.

91. Todd J, Dewhurst K. The double: its psycho-pathology and psycho-physiology. J Nery Merit Dis 1955; 122: 4755.

92. Tong F. Out-of-body experiences: from Penfield to present. Trends Cogn Sci 2003; 7: 104-106.

93. Tononi G. Consciousness, information integration, and the brain. Prog Brain Res 2005; 150: 109.

94. Uddin LQ, Kaplan JT, Molnar-Szakacs 1, Zaidel E, lacoboni M. Self-face recognition activates a frontoparietal "mirror" network in the right hemisphere: an eventrelated fMRI study. Neuroimage 2005; 25: 926935.

95. Vaina LM, Gross CG. Perceptual deficits in patients with impaired recognition of biological motion after temporal lobe lesions. Proc Natl Acad Sci USA 2004; 101: 16947-16951.

96. Vallar G, Sterzi R, Bottini G, Cappa S, Rusconi ML. Temporary remission of left hemianesthesia after vestibular stimulation. A sensory neglect phenomenon. Cortex 1990; 26: 123-131. 
96. Vogeley K, May M, Ritzl A, Falkai P, Zilles K, Fink GR. Neural correlates of first-person perspective as one constituent of human self-consciousness. J Cogn Neurosci 2004; 16: 817-827.

97. Von Baumgarten RJ, Baldrighi G, Shillinger GL, Harth 0 , Thuemler R. Vestibular function in the space environment. Acta Astronaut 1975; 2:49-58.
98. Wilson M. Six views of embodied cognition. Psychon Bull Rev 2002; 9: 625-636.

99. Weiskrantz L. Fragments of memory. Neuropsychologia 1997; 35: 1051-1057.

100. Zacks J, Rypma B, Gabrieli JD, Tversky B, Glover GH. Imagined transformations of bodies: an fMRI investigation. Neuropsychologia 1999; 37: 1029-1040. 